\title{
Cinnarizine in refractory migraine prophylaxis: efficacy and tolerability. A comparison with sodium valproate
}

Mansoureh Togha · Masoud Rahmat Jirde •

Kiafar Nilavari · Hosein Ashrafian · Soodeh Razeghi •

Leila Kohan

Published online: 4 June 2008

(C) Springer-Verlag 2008

Erratum to: J Headache Pain (2008) 9:77-82

DOI 10.1007/s10194-008-0013-2

The first author's given name and family name were transposed. His correct name is Mansoureh Togha.

The online version of the original article can be found under doi:10.1007/s10194-008-0013-2.

M. Togha $(\bowtie) \cdot$ K. Nilavari · H. Ashrafian · S. Razeghi ·

L. Kohan

Department of Neurology,

Medical Sciences/University of Tehran, Sina Hospital,

Imam Khomeini St, 11367-46911 Tehran,

Islamic Republic of Iran

e-mail: toghae@sina.tums.ac.ir

M. Rahmat Jirde

Department of Neurology,

Gorgan University of Medical Sciences,

Gorgan, Islamic Republic of Iran 